\title{
DEVELOPMENT OF ERP SOFTWARE FOR MSME APPAREL INDUSTRY
}

\author{
SOBIKA T G ${ }^{\mathbf{1}} \boldsymbol{\&}$ RAGAVI $\mathrm{A}^{\mathbf{2}}$ \\ ${ }^{1}$ Student, Apparel and Fashion Design, PSG College of Technology, Tamil Nadu, India \\ ${ }^{2}$ Assistant Professor, Apparel and Fashion Design, PSG College of Technology, Tamil Nadu, India
}

\begin{abstract}
India is one of the world's largest textile manufacturer and exporter. The apparel industry contributes $2.3 \%$ to India's GDP. The Micro Small Medium Enterprises (MSME) sector plays an important role in the Indian economy. They contribute $8 \%$ of GDP; more than 90\% of the enterprises in India are MSMEs. ERP software is a software architecture that facilitates the flow of information among the different functions within an enterprise. Cloud-based computing is a revolution in the IT-market. ERP systems delivered as Software as a Service (SaaS) is receiving more focus from ERP vendors. The study aim is to design an ERP software which is functional and user friendly for MSME apparel companies. The software is designed within the restricted amount given by the buyer. This software development will help the MSME apparel industries to examine the ERP system at a low cost, develop the knowledge and skills on the ERP system.
\end{abstract}

KEYWORDS: ERP implementation\& ERP software development

Received: Jul 04, 2020; Accepted: Jul 24, 2020; Published: Sep 11, 2020; Paper Id.: IJTFTAUG20207

\section{INTRODUCTION}

Enterprise Resource Planning (ERP) system is an iterative system for identifying, analysing, evaluating, testing and monitoring the entire process of an organization or a company ${ }^{[2]}$. To obtain seamless integration of information flow across departments and to increase efficiency the organisation has been introducing ERP system since the $1990 \mathrm{~s}{ }^{[16]}$.

The development of IT on cloud computing has revolutionised the market. The product can now be distributed as a service. ERP is now available SaaS "system as a service", where the customer pays the monthly subscriptions to access the software. The ERP SaaS can be accessed through the internet from any location. SaaS is gaining acceptance, but distributing service is more complicated than distributing product because of the immateriality and integration. Few factors that are affecting the adoption of SaaS are cost, security, availability, usability, implementation, ubiquity, flexibility, compatibility, analytics and best practices. The Traditional ERP system has advantages like lower cost of ownership, security and confidentiality of data than SaaS. ERP SaaS requires a stable network connection but it is stated that SaaS is quick and easily adapted to customer requirements [3].

ERP market is one of the fast-growing markets in the IT industry with an average growth rate of $30 \%$ to $40 \%$ yearly ${ }^{[8]}$. Worldwide ERP market revenue was $\$ 267$ billion in 2012 which is $9 \%$ growth over 2011 and is projected growth for 2013 was $\$ 288$ billion ${ }^{[9]}$. Indian ERP market annual growth rate was 25.2\% during 2004-2009. The market value was $\$ 83$ million in 2004 and the projected value was $\$ 160$ million in $2012^{[11]}$.

ERP systems are widely used in developed countries like USA, Canada, the UK and Australia. North America holds $66 \%$ of the ERP market, Europe holds $22 \%$ while Asia holds only $9 \%$ of the market. The developed 
countries have a solid industrial base, strong information infrastructure and quality employees. In Japan, they build their systems in-house or modified the existing system. In developed countries, large corporations have implemented ERP system to achieve a competitive edge in their business. The main interest of IT has now moved towards SME and noncommercials sectors. The development of the open-source ERP system has a huge impact on SME. This development has made the ERP system cost-effective and available to SME (Small Medium Enterprise). It is stated that the implementation of the open-source ERP system showed a $10 \%$ increase in margins and doubling the revenue. Also, increase in performance due to improvement in the order, inventory and invoicing processes ${ }^{[8]}$.

The Micro, Small and Medium Enterprises Development Act, 2006, defines MSMEs based on investments in plant and machinery. For enterprises engaged in the manufacturing (based on investment in plant and machinery):

- $\quad$ Micro - less than Rs 2.5 million

○ $\quad$ Small - over Rs 2.5 million but not exceeding Rs 50 million

- Medium - excess of 50 million limits but less than Rs 100 million ${ }^{[18]}$.

Despite having high implementation challenges and high cost of implementation, the ERP system has gained popularity among large and smaller companies. As a result of having limited resources of finance and IT, lack experience and skills, there is a high rate of unsuccessful ERP implementation in SMEs ${ }^{[5]}$. It is stated that there is a direct relationship between the amount invested in the ERP system and the size of the company ${ }^{[6]}$.

The ERP system implementation failures can also take place because of unrealistic project deadlines, budget estimations and lack of training. The misfit between the organisation and the ERP system, rejects the ERP system implemented at the early stage itself. These rejections take place when a proper ERP system is not selected in the first place $^{[4]}$. ERP system selection should consider looking at the system compatibility, system complexity, transactional efficiency, system adaptability, software training, customisation of the software and employee empowerment factor ${ }^{[9]}$.

Cost budgeting, accurate capital budgeting in ERP implementation is a difficult procedure. Especially when projecting indirect costing. Customisation of the software, poor system requirements analysis and system design process increases the implementation cost ${ }^{[4]}$. Implementation requires money, time and lots of people efforts. ERP software should be appropriately selected based on the business needs and should be evaluated in these categories - functional, operational, technical and economic aspects ${ }^{[6]}$.

The ERP implementation strategies would include a) Phased rollout, b) Pilot study, c) Parallel adoption, and d) Big bang or direct cutover e) AIM methodology. A vanilla implementation usually keeps the BPR to the minimum and follows the core ERP functionalities and process models, instead of customizing the ERP to accommodate and fit the unique processes of the enterprise.

The easier it is the integration with retained systems there will a greater chance of realizing organizational benefits as well the more compatible the ERP is with remaining hardware and software, so the user will be more satisfied ${ }^{[9]}$. The product features and the capacity of the software should be understood by the SMEs company. Without proper training, $30 \%$ to $40 \%$ of the user will not be able to handle the demands of the system. Employees must be committed to their training.

ERP is perceived as being most efficient, where reliability and effectiveness on the application improve user confidence. 
businesses rely on tight communication and collaboration within the firm's departments, suppliers, partners, and customers, applications that empower users through collaboration and thereby productivity is increased ${ }^{[9]}$.

\section{METHODOLOGY}

\subsection{Target Market}

Micro Small Medium Enterprises (MSMEs) are selected as the target market. Tirupur is a centre for the cotton market, which is also known as the Banian City or the Knit City. About $80 \%$ of the Indian's total knitwear exports are from Tirupur.

There are approximately 6250 units in Tirupur, in which 2500 are garment manufactures. Among 2500 units, 500 units are large size with more than 500 sewing machines and mainly exporting. 500 units which are medium size with 40 to 100 sewing machines, they supply export and domestic market. There are 1500 small size unites which has 40 or less sewing machines, they supply the domestic market and do sub-contracting from medium or large size units ${ }^{[21]}$.

\subsection{Identifying the Existing Software in The Market.}

Identifying the software's used in the market is done to understand the following.

- $\quad$ the features offered by the software

- $\quad$ who will be using the software?

- $\quad$ whether all the features in the software is known and used efficiently

- $\quad$ the pricing of the software

The software in the market will help to analyse the development of the ERP in the market. Few industries were visited and the following data were obtained.

\section{Industry A}

The software used by this industry is OMS ERP software by Idea Tec. The software features include planning, billing, and monitoring the order in the company. This software contains all the step-by-step processes being from merchandising to marketing. From the figure 1, is the home screen OMS ERP Software.

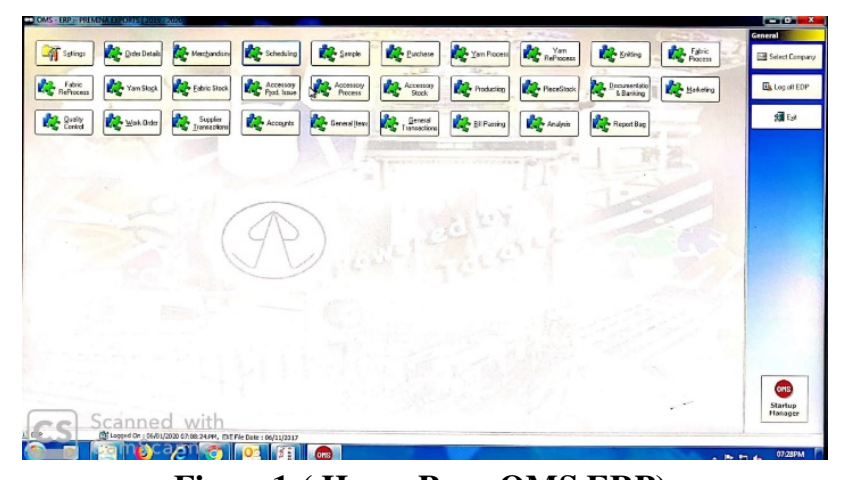

Figure1:( Home Page OMS ERP)

Under merchandising, there areoptions like approval submission, approval receipt and reports of approval status, delivery status. Under order, there are options like material planning, accessory planning, production planning and their reports. Under sample, order sheet, material planning for sample and sample order status are available. Under general 
itemsthe purchase order, purchase inward, purchasee outward, issues and reports of purchases in and out, stocks can be seen.

This software contains all the features but the company does not utilise this software to its full efficiency due to the company's limited technical knowledge and lack of systematic structure. This software in the company is used only by the billing team and accounts department. The software costs around $\square 1,50,000$ but the current version of the software is around $\square 3,00,000$.

\section{Advantage -}

- $\quad$ Contains all the features from receiving the order till finishing.

- User-friendly interface

\section{Disadvantage -}

- $\quad$ Can be used by the person only if they have basic knowledge on billing

- $\quad$ This software does not have mobile app or clouds computing service

\section{Industry $B$}

The software used by this industry is Tally Server by Tally. This is an Accounting software. They have a feature like inventory management, stock management, invoicing, purchasing, order management, discounting, stock valuation methodology and accounting principles.

This software helps in maintaining proper accounts. This helps us to know the financial position of the company. This displays accounts receivable, payables, bank reconciliation, cash flow management, interest payment and record keeping (figure 2). This software is used by the people in the accounting department. It includes Managing Director, General Manager, Cost Accountant, accountants etc. This software recent version Tally server 9 is $\square 2,70,000+18 \%$ GTS $(\square 48,600)$

\section{Advantage -}

- $\quad$ User-friendly interface

\section{Disadvantage -}

- $\quad$ Can be used by the person only if they have basic knowledge on accounts

- $\quad$ This software contains features that are required by the accounts department

- $\quad$ This software does not have mobile app or clouds computing service 


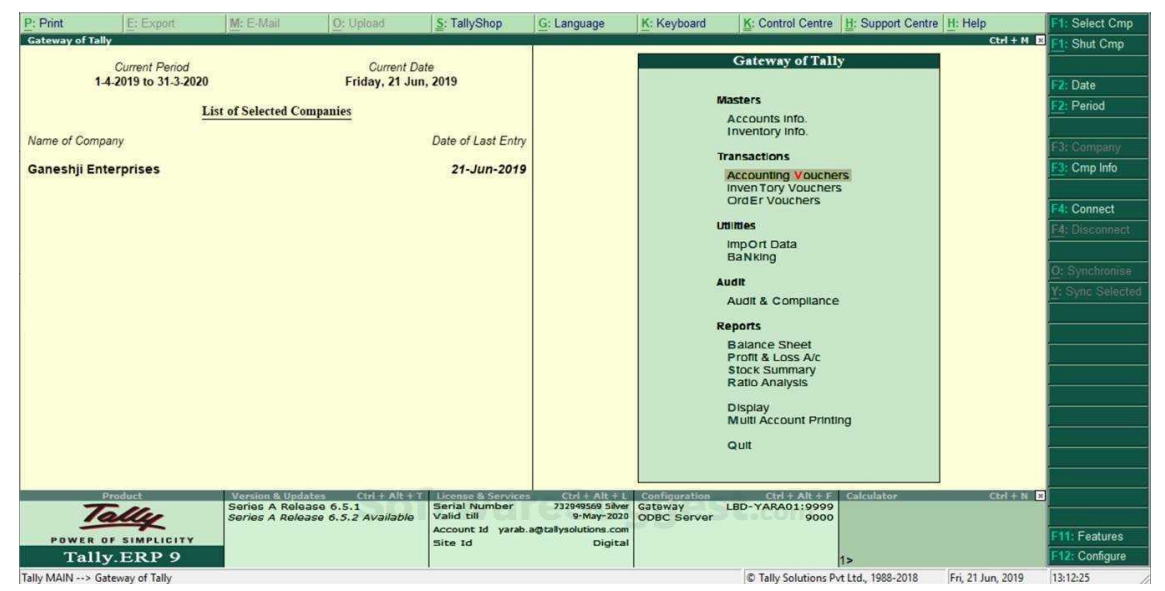

Figure2: (Home page Tally)

\section{Industry C -}

The software used by the industry is Microsoft Excel. This features analytical functions like pivot table, graphs and decision analytics. It has formula groups and nested functions; because of this major financial calculation can be done. It also has conditional formulae like logic, lookup, indirect and match functions, which helps in data analysis and what-if analysis.

This software is used by both small and medium companies. This software costs around $\square 4500$. This software comes along Microsoft word, power point and outlook. Different version of this software is available.

\section{Advantage -}

- $\quad$ Can be used by everyone with basic computer knowledge

\section{Disadvantage -}

- $\quad$ Limited features available with the software.

\subsection{Identify the Need for the Software}

The survey was conducted to understand the following.

- whether there is a need for ERP software by target market

- $\quad$ to know their monitoring methods

- the problem faced during order tracking

- $\quad$ the software's currently used

The following are the results from the questionnaire collected for 19 industries. This questionnaire contained 23 questions. This questionnaire is collected particularly from industries located in Tirupur.

- $\quad 73.7 \%$ of the industries produce t-shirts (Figure 3)

- $\quad 68.4 \%$ of the industries comes small scale (Figure 4)

- $\quad 42.1 \%$ of the industries carry 1 to 5 and $42.1 \%$ of the industries carry 6 to 15 orders simultaneously (Figure 5) 

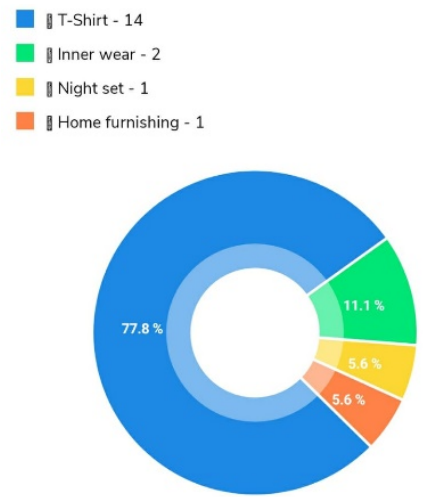

Figure 3: (Products category)

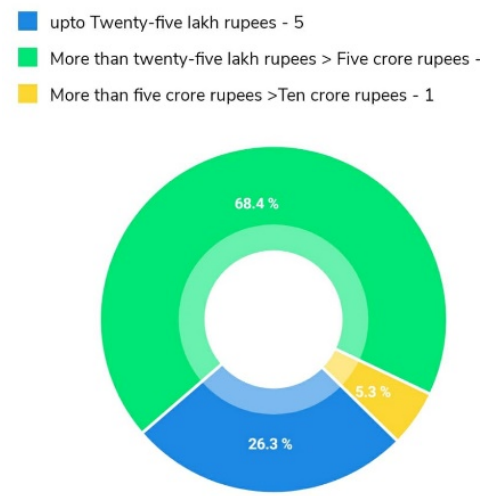

Figure 4 (Investment)
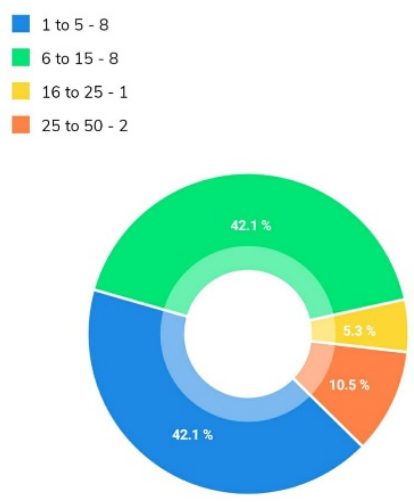

Figure 5 (Orders)
In-house production - 11
CMT - 0
Both - 8

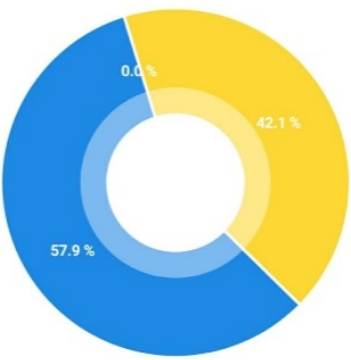

Figure 6 (Production method)

$$
\begin{aligned}
& \text { Daily - } 11 \\
& \text { Weekly - } 8
\end{aligned}
$$

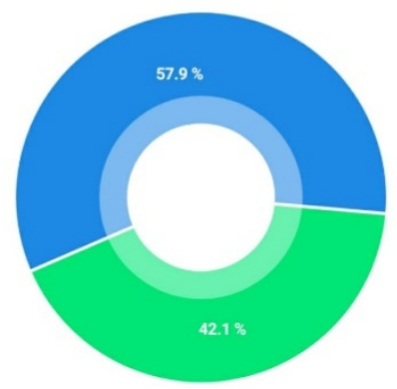

Figure 7 (Recording Activities)

- $\quad 73.7 \%$ of industries use time and action plan every time (Figure 9)

- $\quad 57.9 \%$ of the industries do in-house production and $42.1 \%$ of the industries do both in-house production and through CMT parties (Figure 6)

- $\quad 57.9 \%$ of the industries do record the activities daily (Figure 7)

$$
\begin{aligned}
& \text { Yes - } 14 \\
& \text { No- } 5
\end{aligned}
$$

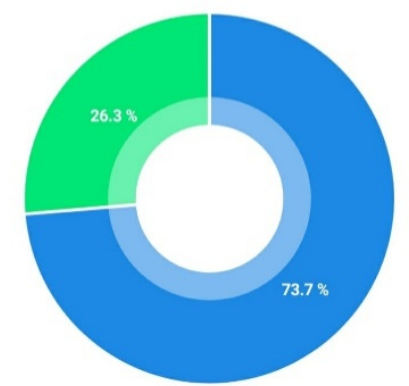

Figure 9 (Products)

$$
\begin{aligned}
& \text { Yes - } 10 \\
& \text { No-0 } \\
& \text { Maybe-9 }
\end{aligned}
$$

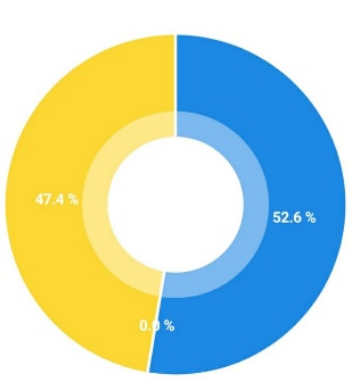

Figure 10 (Investment)
Mobile app - 7
Computer application - 12

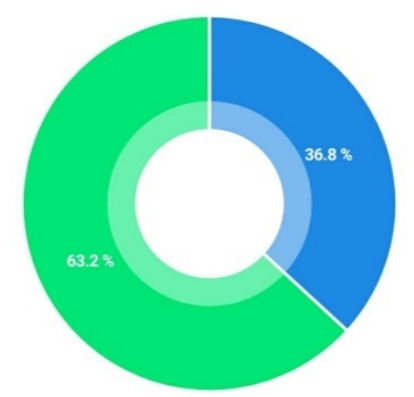

Figure11 (Orders)

- $\quad 73.7 \%$ of the industries record the activities through the system (Figure 8)

- $\quad 52.6 \%$ are willing to try the new order tracking software (Figure 10)

- $\quad 63.2 \%$ are willing to have the software as computer application (Figure 11) 


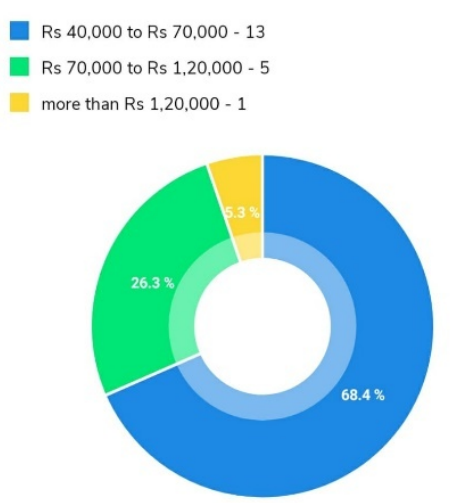

Figure 12 (Pricing)

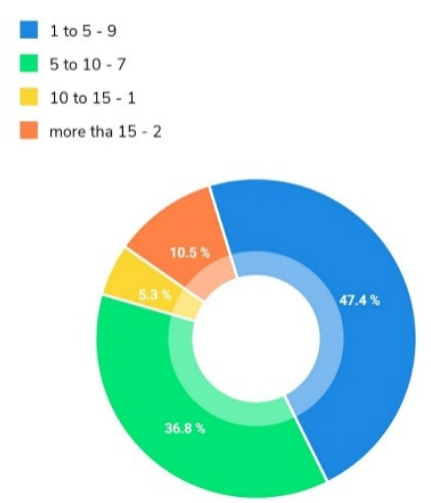

Figure 13 (Accessing)
One time Purchase - 16
Monthly subscription - 3

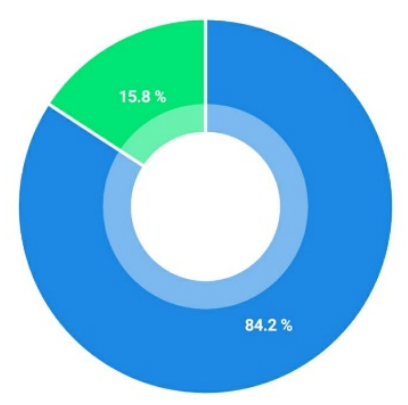

Figure 14 (Purchasing)

- $68.4 \%$ industries are willing to spend $\square 40,000$ to $\square 70,000$ on the software (Figure 12)

- $\quad$ In $47.4 \%$ of the industries 1 to 5 people will be accessing the software (Figure 13)

- $\quad 84.2 \%$ of the industries wanted the software as one time purchase (Figure 14)

- $\quad$ Cutting, sewing, ironing and packing are mostly available in industries (Figure 15)

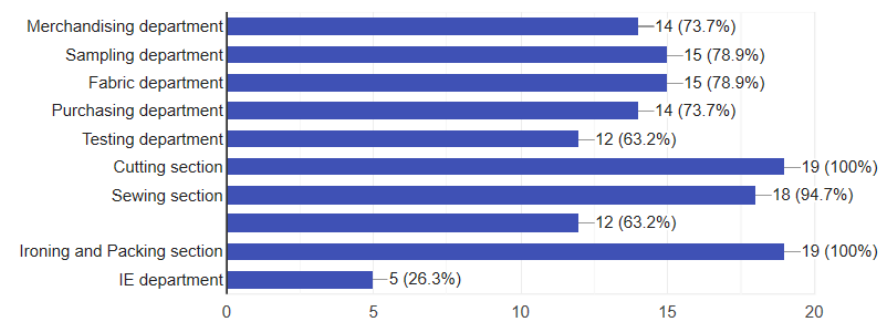

Figure 15: (Departments)

- $\quad$ Mixing up of labels and tag is the major problem followed (Figure 16)

- $\quad 78.9 \%$ are asking for time and action plan (Figure 17)

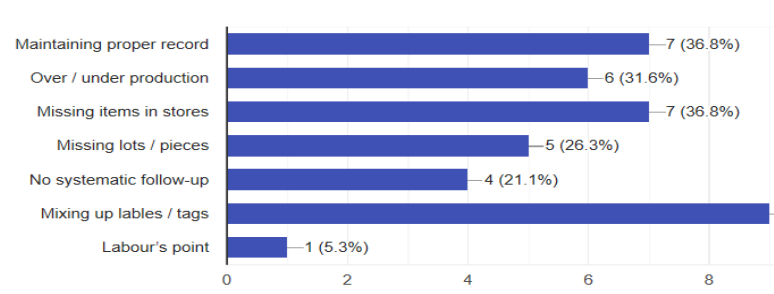

Figure 16: (Problems)

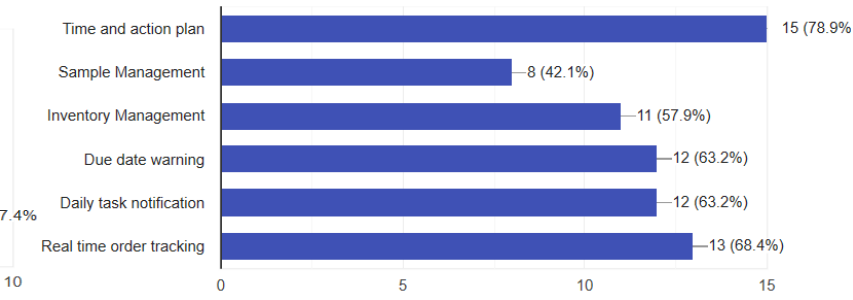

Figure 17: (Features)

\subsection{Development of The Software}

The development of the software is divided into two stages, first designing the application and second development of the application. In the designing stage, the process flow of the order in the industry and the entry point in the order is studied. For this study, one industry selected from the target market. 
About the industry, company name PREMINA EXPORTS located in Tirupur district. The industry has sample department, fabric department, production development and Accessories / store department. They also have printing department opened recently. Their daily average production is 10,000 pieces. They produce through both in-house production and through CMT parties. They outsource for processes like dyeing, bleaching, compacting and printing are done out in local industries.

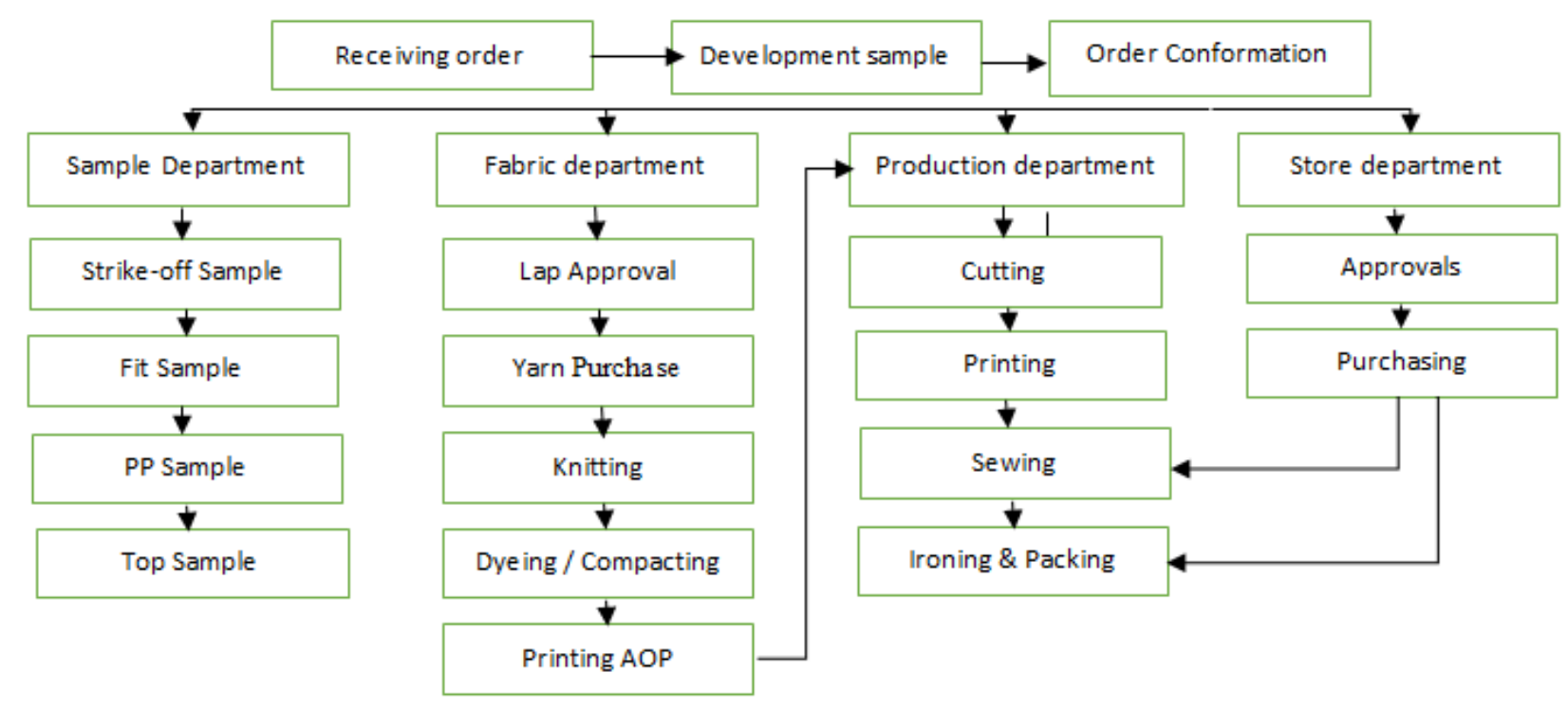

Mapping of the Industry Process

All the departments in the industry work simultaneously to finish the order. From the above flow chart, the process flow of the order is understood. Based on the survey conducted it is understood that the following features are needed.

- $\quad$ Order tracking system

- $\quad$ Time and Action Plan

- User-friendly

The software designed should be under the budget limited by the buyer ( $\square 70,000)$. Everyone with basic knowledge on how use mobile should be able to use the software. The following are the basic details in the order sheet.

- Order No. - The number given for the particular purchase or order by the buyer. This number helps to identify the order. They many contain alphabets and numbers.

- Style No. - Each order will have variety of styles, each style in the order is given particular number to identify the style. They many contain alphabets and numbers.

- Due Date - This is the date given by the buyer to finish the order and make the order ready for shipment.

- $\quad$ Order Details - Its contains details about the colour, printing, stitch details, labels, tags, packing and shipment.

Development stage - The software has been developed as a web app application which can be viewed on both computer system and mobile phones. This application is stored in a cloud server. Following are the images from the developed 
software.All the changes and updates are stored in the cloud server.

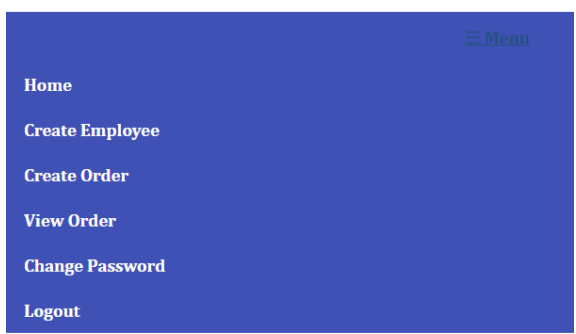

Welcome

Admin !!!!

Current Date

14-04-2020

Current Time

22:21

Figure 18: (Home page Admin)

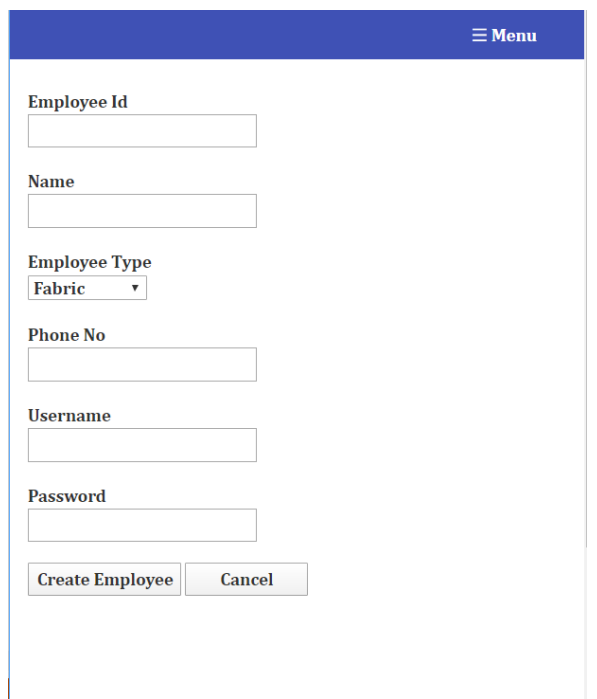

Figure 19: (Create employee)

In the home page of the Admin (Figure 18) there are options in the menu like create order, create employee, to view order, change password and to logout. In the, Create Employee (Figure 19), the employee can be created by entering details of the employee like employee Id, name, employee type, phone number, username and password. Once the employee is created, they can use the user name and password to login and view the order details. This data's will be stored in the cloud server.

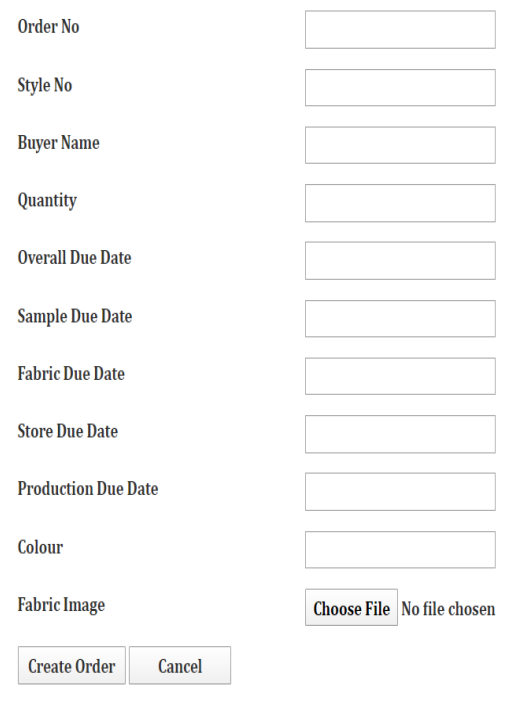

Figure 20: (Create Order)

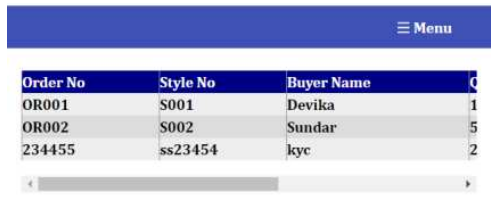

Figure 21: (View Order)

Create order (Figure 20), there the order can be created by entering the details like order no., style no., buyer name, quantity, overall due date, sample due date, fabric due date, production due date, store due date, colour and the image of the garment can be also added.Once the order is created, the order will be visible in the view order status(Figure 21).The view orderstatus contain details of all the current orders. Details like order no., style no., buyer name, quantity and due date are visible in a tabular form. The admin can change the password of the admin account by entering the old password and then the new password and save. The admin can logout by clicking the logout button in the menu. 


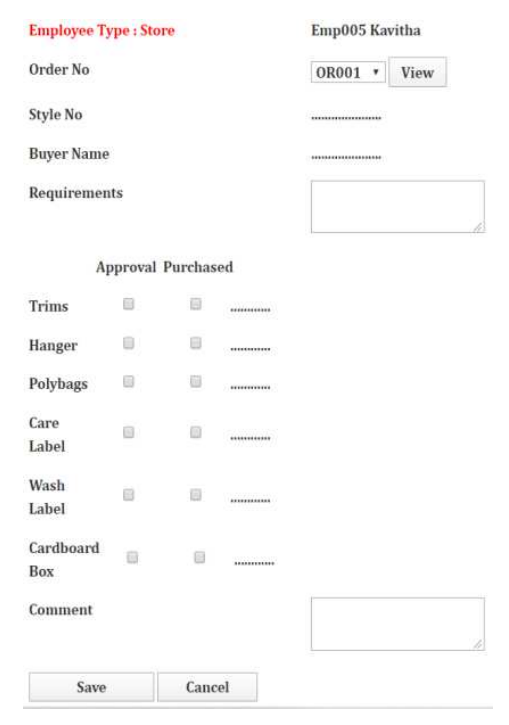

Figure 22 (Store Home Page)

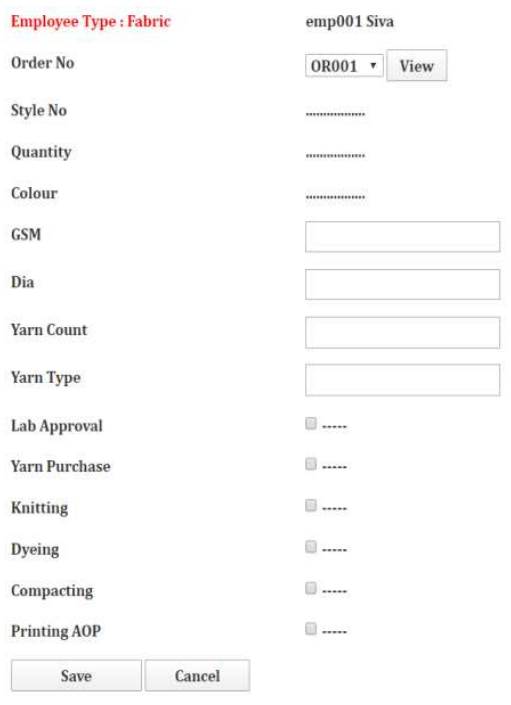

Figure 23 (Fabric home Page)

The store employee(Figure 22), when the particular order no is selected the employee can view the details of the order. The details like style no., buyer name will be visible. These details are entered by the admin while creating the order. The requirement box can be filled based on the buyer's requirements by the employee. There are two columns checkbox, one for approvals and the other for purchase. Once the purchase or approval is done, one can click the checkbox to show the work has been finished which will be visible with the dates and can be updated in the server. There is a comment box to enter the comment on the order by the buyer or by the admin. In the menu option, the employee can see the current order details with the due date for the completion order. The due date order changes from one department to other department.

The fabric employee (Figure 23), order details like order no., style no., buyer name and quantity can be viewed. The GSM, fabric dye, yarn count and yarn type are entered by the employee based on the order planning. Here arecheckboxes for the lab approval of the fabric and for each the fabric processing. Once the process is done, the employee can update the order status.

The sample employee (Figure 24), here the details of the order like order no., style no., buyer name and picture of the garment are visible. The employee can click the checkboxes if the work is completed. The comments can be entered in the comment box if anything is mentioned by the buyer and be saved for references. The production employee (Figure 24), here the details like order no., style no., buyer name, picture of the garment can be viewed and the requirements box can be filled based of the buyer's requirements. This requirements can be changed if the buyer changes or if any changes given by the admin. The checkboxes clicked once the work is done which will be visible with date it updated. The weights of the order can be also entered here for future references. 


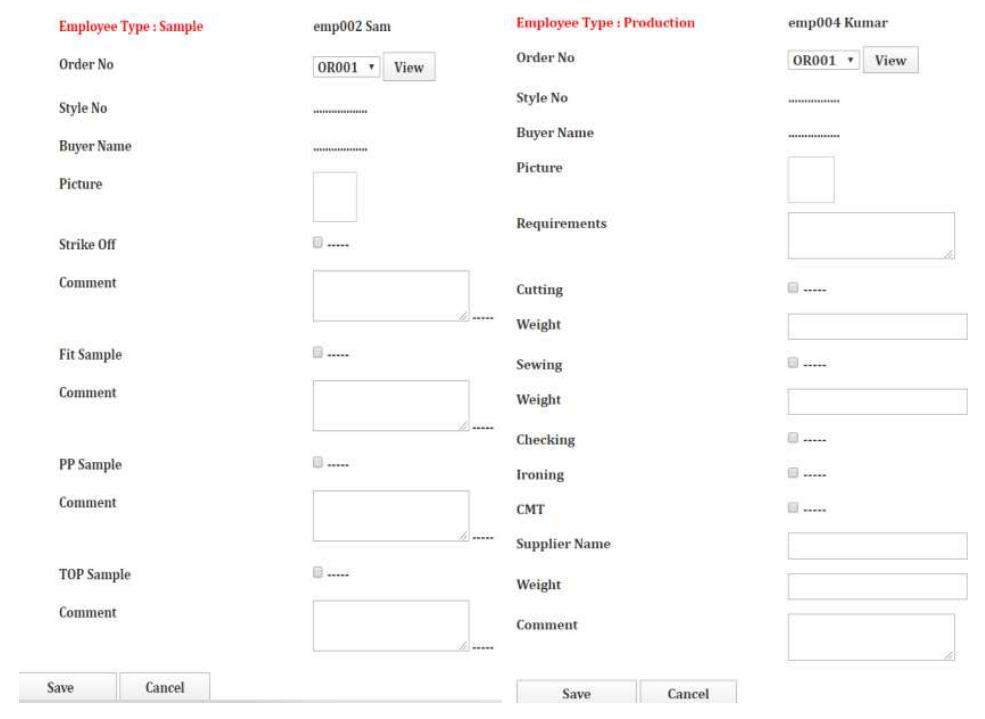

Figure 24: (Sample Home Page)

Figure 25: (Production Home Page)

The development of the software cost around $\square 10,000$. It includes the software coding andtemporary cloud storage for one month. The real software would cost around $\square 30,000$ with yearly $\square 10,000$ for the cloud storage. The software can be used through a shared database or server in a company but has a drawback the software will not be functional in mobile phones.

\section{RESULTS}

The software was examined by an industrial person and the feedbacks were collected on the software. They mentioned adding few more features into the software to make the software work more realistic and efficient for daily usage. The features are like uploading the order details and buyer's comments through excel sheet. The software pricing can be reduced by selling the software to other companies in the target market.

The software is developed as an order tracking software which can be used by the management and the production departments in the MSME apparel industries. The software implementation is easier and requires minimum changes in the industry. This software helps employee to follow up the orderwithout any communication defects. This software is not expensive compared to other ERP software in the market. Therefore,this software has an advantage over other software. This software helps in maintaining and monitoring the dataof the order online.

\section{REFERENCES}

1. https://www.investindia.gov.in/sector/textiles-apparel

2. Anubhav Kumara, P C Guptab, 'Identification and Analysis of Failure Attributes for an ERP System', Procedia - Social and Behavioral Sciences 65, 2012, 986 - 991.

3. Björn Johansson, Pedro Ruivo, 'Exploring Factors for Adopting ERP as SaaS', Procedia Technology 9, $2013,94-99$.

4. Ahmed Elragal, MoutazHaddara, 'The Future of ERP Systems: look backward before moving forward', Procedia Technology 5, 2012, $21-30$.

5. Khan, M. Z. H. (2017). A case study on Occupational health and safety of footwear manufacturing industry. Journal of Business and GeneralManagement, 2, 1-6.

6. Eli Hustada, Dag H. Olsen, 'Critical Issues across the ERP Life Cycle in Small-and-MediumSized Enterprises: Experiences 
from a Multiple Case Study', Procedia Technology 9, 2013, 179 - 188.

7. Augusto A Pacheco-Comer, Juan C González-Castolo, 'An empirical study in selecting Enterprise Resource Planning Systems: The relation between some of the variables involve on it. Size and Investment', Procedia Technology 3, 2012, 292 - 303.

8. Rahman, S. A., \& Shohan, S. Supplier Selection Using Fuzzy-Topsis Method: A Case Study In A Cement Industry.

9. Momin Mukherjee, Sahadev Roy, 'On Successful Implementation of ERP Software', International Journal of Advanced Engineering and Management Vol. 2, No. 1, 2017, pp. 28a-28c.

10. Shisam Bhattacharyya, Pranab K. Dan, 'Trends in ERP Software and Justification for Development of Open Source Systems for Small-scale Businesses', Asia-Pacific Journal of Management Research and Innovation 10(4), 2014, 423-433.

11. Pedro Ruivo et al, 'Commercial ERP systems and user productivity: A study across European SMEs', Procedia Technology 9 , 2013, $84-93$.

12. Zhenyu Huang, PrashantPalvia, 'ERP implementation issues in advanced and developing countries', Business Process Management Journal, Vol. 7 No. 3, 2001, pp. 276-284.

13. PoonamGarg, ReemaKhurana, 'ERP product selection criteria for Indian small and medium enterprises: an empirical study', Int. J. Business Information Systems, Vol. 14, No. 4, 2013.

14. Majed Al-Mashari, Abdullah Al-Mudimigh, 'ERP implementation: lessons from a case study', Information Technology \& People Vol. 16 No. 1, 2003, pp. 21-33.

15. Mohamed-IliasseMahraz, 'Implementation and Management of ERP Systems: A Literature Review', Proceedings of the International Conference on Industrial Engineering and Operations Management Bandung, Indonesia, March 6-8, 2018.

16. C. Annamalai, T. Ramayah, 'Enterprise resource planning (ERP) benefits survey of Indian manufacturing firms An empirical analysis of SAP versus Oracle package', Business Process Management Journal Vol. 17 No. 3, 2011, pp. 495-509.

17. H. S. C. Perera, W. K. R. Costa, 'Analytic Hierarchy Process for Selection of Erp Software for Manufacturing Companie', VISION - The Journal of Business Perspective Vol. 12, No.4, October-December 2008.

18. Karoline B. Osnes et al, 'ERP System in Multinational Enterprises: A literature Review of Post - implementation Challenges', Procedia Computer Science 138, 2018, 541-548.

19. http://newhorizonindia.edu/nhc kasturinagar/wpcontent/uploads/2017/03/MSM.pdf

20. Chauhan, S. S., Ajitsaria, S. K., Kumar, G., \& Khan, M. D. COMPACT HUMAN ARM FOR MEDICAL AND INDUSTRIAL USE.

21. Shailja Dixit, 'Enhancing The Competitiveness of Textile Industry in an Emerging Economy : The Role of Msme', Samvad Volume IX, March 2015.

22. R. Basu et al., 'Factors influencing ERP implementation in Indian SMEs: An empirical analysis', Management Science Letters 1, 2011, 89-98.

\section{3. https://www.erpaq.com/}

24. Kavitha, S., \&Manimekalai, G. (2014). A study on waste disposal management in garment industry. International Journal of Textile and Fashion Technology (IJTFT), 4(5), 37-42.

25. https://www.newclothmarketonline.com/the-development-of-apparel-industrial-cluster-in-india-a-comparison-betweenludhiana-tirupur/

26. https://shodhganga.inflibnet.ac.in/bitstream/10603/171813/10/10_chapter\%204.pdf 